\title{
Effects of a Chinese Herbal Medicine, Guan-Jen-Huang (Aeginetia indica Linn.), on Renal Cancer Cell Growth and Metastasis
}

\author{
Yu-Huei Liu, ${ }^{1,2,3}$ Meng-Luen Li, ${ }^{1}$ Meng-Yu Hsu, ${ }^{1}$ Ya-Yueh Pang, ${ }^{1}$ I-Ling Chen, ${ }^{1}$ \\ Ching-Kuei Chen, ${ }^{1}$ Sai-Wen Tang, ${ }^{1}$ Hsuan-Yuan Lin, ${ }^{1}$ and Jung-Yaw Lin ${ }^{1}$ \\ ${ }^{1}$ Institute of Biochemistry and Molecular Biology, College of Medicine, National Taiwan University, Taipei 100, Taiwan \\ ${ }^{2}$ Department of Medical Genetics and Medical Research, China Medical University Hospital, Taichung 404, Taiwan \\ ${ }^{3}$ Graduate Institute of Integrated Medicine of Chinese Medicine, China Medical University, Taichung 404, Taiwan
}

Correspondence should be addressed to Jung-Yaw Lin, linjy@ntu.edu.tw

Received 19 April 2011; Revised 9 August 2011; Accepted 9 August 2011

Academic Editor: Vincenzo De Feo

Copyright (c) 2012 Yu-Huei Liu et al. This is an open access article distributed under the Creative Commons Attribution License, which permits unrestricted use, distribution, and reproduction in any medium, provided the original work is properly cited.

\begin{abstract}
Aeginetia indica Linn. (Guan-Jen-Huang, GJH), a traditional Chinese herb, has the potential to be an immunomodulatory agent. The purpose of this study was to explore the effect of GJH in the treatment of renal cancer. Concentration-effect curves for the influence of GJH on cellular proliferation showed a biphasic shape. Besides, GJH had a synergistic effect on cytotoxicity when combined with 5-fluorouracil (5-FU)which may be due to the alternation of the chemotherapeutic agent resistance-related genes and due to the synergistic effects on apoptosis. In addition, treatment with GJH extract markedly reduced 786-O cell adherence to human umbilical vein endothelial cells (HUVECs) and decreased 786-O cell migration and invasion. In a xenograft animal model, GJH extract had an inhibitory effect on tumor cell-induced metastasis. Moreover, western blot analysis showed that the expression of intercellular adhesion molecule-1 (ICAM-1) in 786-O cells was significantly decreased by treatment with GJH extract through inactivation of nuclear factor $-\kappa \mathrm{B}(\mathrm{NF}-\kappa \mathrm{B})$. These results suggest that $\mathrm{GJH}$ extract has a synergistic effect on apoptosis induced by chemotherapeutic agents and an inhibitory effect on cell adhesion, migration, and invasion, providing evidence for the use of water-based extracts of GJH as novel alternative therapeutic agents in the treatment of human renal cancer.
\end{abstract}

\section{Introduction}

Renal cell carcinoma (RCC) is the most common solid lesion found within the kidney and accounts for approximately $90 \%$ of renal malignancies [1]. Despite improvements in diagnostic techniques and treatment strategies, currently there is no evidence that the use of targeted therapies, alone or in combination with adjuvant treatments, treats localized RCC and improves overall survival. However, 4 large randomized adjuvant clinical trials are ongoing and will address the feasibility and efficacy of treatment in localized RCC $[2,3]$. In addition, currently licensed target agents are cost-ineffective and have a lot of common side effects. Therefore, a more potent alternative agent is required to achieve acceptable clinical and oncological outcomes.

Metastasis, a common feature of RCC, is a multistep process that leads to the development of secondary tumors.
Preventing the occurrence of any of these steps would prevent metastasis [4]. During the metastatic cascade, primary tumor cells digest their surrounding extracellular matrix, migrate through interstitial spaces, and enter the blood or lymphatic vessels where they are carried to distant organs [5]. The adhesion of circulating tumor cells to the microvascular endothelium of organs at distant sites is an important step in metastasis. Once lodged in the target organs, these cells migrate into the interstitial spaces and continue to grow and develop a secondary tumor, or they metastasize [6]. Thus, the adhesion, migration, and invasion of cancer cells provide many potential targets for therapeutic intervention.

Increasing evidence suggests that some medicinal herbs may decrease the risk of malignancies. Studies have shown that phytochemicals contained within herbs are promising chemopreventive agents. Aeginetia indica Linn. (Chinese name "Guan-Jen-Huang", GJH), a root parasitic plant, has 
been used as folk medicine in Taiwan and other countries to treat chronic liver diseases, cough, and arthritis. The seed extract of GJH induces potent antitumor immunity [7-9]. This formula is used as health food even today, and several studies have demonstrated the antitumor effect of a $55-\mathrm{kDa}$ protein isolated from the seed of GJH $[8,10-12]$. However, the effects of GJH herbal extract in human cancers remain to be determined.

In the present study, we report that a water-based extract of GJH inhibits tumor growth and metastasis. The treatment of 786-O renal carcinoma cells with GJH resulted in a synergistic effect on 5-fluorouracil (5-FU)-induced apoptosis, inhibition of cell migration and invasion, and reduction in cell adherence to endothelial cells. The molecular mechanisms involved in these effects include the downregulation of chemotherapeutic agent resistance-related genes and intercellular adhesion molecule-1 (ICAM-1) expression, in parallel with the reduction of nuclear factor- $\kappa \mathrm{B}$ (NF- $\kappa \mathrm{B}$ ) expression and activation.

\section{Materials and Methods}

2.1. Plant Extracts. GJH plants were approved and extracted by Sun Ten Pharmaceutical Company (Taipei, Taiwan). In brief, dry plant materials were finely ground, and the extracts were prepared by boiling $250 \mathrm{~g}$ of plant material in $1250 \mathrm{~mL}$ of water for $30 \mathrm{~min}$. The extracts were concentrated to $250 \mathrm{~mL}$ with an evaporator at room temperature. The extract was then centrifuged at $3000 \mathrm{rpm}$ for $10 \mathrm{~min}$ and filtered through a $0.45-\mathrm{mm}$ syringe filter. Stock solutions at a concentration of $1 \mathrm{~g} / \mathrm{mL}$ were stored at $-20^{\circ} \mathrm{C}$ until use.

2.2. Cell Lines. The RCC cell line 786-O was obtained from the American Type Culture Collection and maintained in RPMI 1640 (Invitrogen) supplemented with 10\% fetal bovine serum (FBS, Invitrogen), $2 \mathrm{mM} \mathrm{L}$-glutamine (Invitrogen), and $100 \mu \mathrm{g} / \mathrm{mL}$ penicillin-streptomycin (Invitrogen). Human umbilical vein endothelial cells (HUVECs) were obtained from the Bioresource Collection and Research Center and maintained in medium 199 (Invitrogen) supplemented with $20 \% \mathrm{FBS}, 25 \mathrm{U} / \mathrm{mL}$ heparin (Sigma), and $30 \mu \mathrm{g} / \mathrm{mL}$ ECGS (Sigma). All cells were maintained in a humidified atmosphere of $5 \% \mathrm{CO}_{2}$ at $37^{\circ} \mathrm{C}$.

2.3. Cell Proliferation Assay. 786-O cells were seeded in 96well plates in serum-reduced medium (1\% FBS) containing various concentrations of GJH $(0-100 \mathrm{mg} / \mathrm{mL})$ at a density of $2 \times 10^{4}$ cells $/ \mathrm{mL}$ per well for $24 \mathrm{~h}$. To investigate the combined effect of GJH and anticancer drugs, 786-O cells were seeded in 96 -well plates at $5 \times 10^{3}$ cells $/ \mathrm{mL}$ per well and incubated for $24 \mathrm{~h}$. On the following day, $100 \mu \mathrm{L}$ aliquots containing GJH and/or the anticancer drugs 5-FU, cisplatin, or paclitaxel (all from Sigma) were added to each well and the cells were cultured for a further $48 \mathrm{~h}$. The number of viable cells was estimated by measuring the conversion of the tetrazolium salt MTT to formazan crystals. After incubation with MTT for $4 \mathrm{~h}$, formazan crystals were solubilized with DMSO and quantified spectrophotometrically by measuring the absorbance at $590 \mathrm{~nm}$ with a reference wavelength of $650 \mathrm{~nm}$.

2.4. Combination Index Analysis. The combined effects of $\mathrm{GJH}$ and anticancer drugs were quantified using a combination index (CI) method developed by Chou and Talalay [13]. This method involves plotting dose-effect curves for each agent and their combination, using the median-effect equation: $f a / f u=(D / D m) m$, where $D$ is the dose of the drug, $D m$ is the dose required for a $50 \%$ cytotoxic effect (equivalent to $\mathrm{CC}_{50}$ ), $f a$ and $f u$ are the affected and unaffected fractions $(f a=1-f u)$, respectively, and $m$ is the exponent signifying the sigmoidicity of the dose-effect curve. The relative concentrations of $\mathrm{GJH}$ and the anticancer drugs, determined as (concentration)/( $\mathrm{CC}_{50}$ value), were used for analysis. The values of $D m$ and $m$ were calculated first. The CI used for analysis of the drug combinations was determined by the equation for mutually nonexclusive drugs that have different modes of action: $\mathrm{CI}=(D) 1 /(D \mathrm{x}) 1+(D) 2 /(D x) 2+$ $(D) 1(D) 2 /(D x) 1(D x) 2$, where $(D) 1$ and $(D) 2$ are relative concentrations of drugs 1 and 2 , and $x$ is the percentage of inhibition. Combination indices CI $<1, \mathrm{CI}=1$ and $\mathrm{CI}>1$ indicate synergistic, additive, and antagonistic effects, respectively.

2.5. Annexin V-Binding Assay. $786-\mathrm{O}$ cells were seeded at a density of $1.0 \times 10^{6}$ cells/well and incubated with the indicated doses of GJH, 5-FU, GJH + 5-FU, or 3\% $\mathrm{H}_{2} \mathrm{O}_{2}$ (as a positive control) for $48 \mathrm{~h}$. Cells were then collected by centrifugation $(1000 \times \mathrm{g}$ for $5 \mathrm{~min})$, washed twice with Annexin V-binding buffer (PBS containing $2.5 \mathrm{mM} \mathrm{CaCl}_{2}$ ), and resuspended in the same buffer. After that, $200 \mu \mathrm{L}$ of the cell suspension was incubated with $5 \mu \mathrm{L}$ of biotinconjugated Annexin V (biotin-Annexin V; Biovision) for $5 \mathrm{~min}$ at room temperature in the dark. The cells were then washed twice with Annexin V-binding buffer and fixed in $200 \mu \mathrm{L}$ of $2 \%$ formaldehyde in PBS for $15 \mathrm{~min}$. After washing twice with PBS, the fixed cells were incubated with horseradish peroxidase (HRP)-conjugated streptavidin (eBioscience) for $30 \mathrm{~min}$ at room temperature. The biotinAnnexin V bound to phosphoserine (PSer) exposed on the cell surface was detected spectrophotometrically using the HRP substrate 3,3',5,5' -tetramethylbenzidine (TMB; eBioscience), by measuring the absorbance at $450 \mathrm{~nm}$ with a reference wavelength of $650 \mathrm{~nm}$.

2.6. Real-Time Quantitative RT-PCR. Total RNA was extracted using TRIzol reagent (Invitrogen) in accordance with the manufacturer's instructions and further digested with DNase I (Promega). The integrity of the RNA was confirmed before quantitative (q) RT-PCR analysis. Then, $1 \mu \mathrm{g}$ of RNA was reverse transcribed in the presence of SuperScript II RT (Invitrogen) and oligo(dT) primers (Invitrogen) at $42^{\circ} \mathrm{C}$ for $1 \mathrm{~h}$ followed by incubation at $70^{\circ} \mathrm{C}$ for $15 \mathrm{~min}$ to inactivate the enzymes. Amplification of the cDNA was performed using SYBR Green PCR Master Mix (ABgene) and analyzed with the iCycler iQ Real-Time PCR Detection System (Bio-Rad). Primers were designed by the Beacon Designer 4 program (Premier Biosoft International) and 
sequences are listed in Table 1 . The PCR conditions comprised an initial denaturation at $95^{\circ} \mathrm{C}$ for $15 \mathrm{~min}$, followed by 40 cycles at $95^{\circ} \mathrm{C}$ for $10 \mathrm{~s}$ and $60^{\circ} \mathrm{C}$ for $45 \mathrm{~s}$. A dissociation procedure was performed to generate a melting curve for confirmation of the amplification specificity. The results were normalized to glyceraldehyde 3-phosphate dehydrogenase. The relative levels of gene expression are represented as $-\Delta \mathrm{Ct}=\left(\mathrm{Ct}_{\text {gene }}-\mathrm{Ct}_{\text {reference }}\right)$, and the fold change in gene expression was calculated by the $2(-\Delta \Delta \mathrm{Ct})$ method (where Ct is cycle threshold) as described previously [14].

2.7. Antibodies and Western Blotting. Antibodies against intact or cleaved forms of of poly (ADP-ribose) polymerase (PARP), $\beta$-catenin, cyclin D1, and ICAM-1 were obtained from Cell Signaling Technology. Antibodies against NF- $\kappa$ B p65 and p50 subunits and Sp-1 were purchased from Santa Cruz Biotechnology. A primary antibody against total actin and goat anti-mouse and goat anti-rabbit HRP secondary antibodies were from Chemicon. Total cell lysates extracted with lysis buffer (50 mM Tris- $\mathrm{HCl}[\mathrm{pH} 8.0], 150 \mathrm{mM} \mathrm{NaCl}$, $0.5 \%$ sodium deoxycholate, $0.1 \%$ sodium dodecyl sulfate [SDS], and 1\% NP-40) containing a protease inhibitor cocktail, or nuclear fraction extracted using the NE-PER Nuclear Protein Extraction Kit (Thermo Scientific), were analyzed. The protein concentration was determined using a BCA protein assay kit (Thermo Scientific). Proteins were separated by $10 \%$ SDS-polyacrylamide gel electrophoresis and transferred to a polyvinylidene fluoride membrane (Immobilon-P, $0.45 \mathrm{~mm}$; Millipore, Billerica, MA, USA) using NA-1512 Semi-Dry Transfer apparatus (NIHON EIDO). The membranes were blocked with $5 \%$ skim milk in Tris-buffered saline containing 1\% Tween 20 (TBST, pH 7.4) at room temperature for $30 \mathrm{~min}$ and incubated overnight at $4{ }^{\circ} \mathrm{C}$ with primary antibody. The membranes were washed 4 times with TBST for 10 min each at room temperature and incubated with HRP-conjugated secondary antibody for $1 \mathrm{~h}$ at room temperature. The membranes were then washed 4 times with TBST. Proteins were visualized using an enhanced chemiluminescence (ECL) kit and western blotting detection reagents (GE Healthcare Life Sciences) and exposed to X-ray film (Fuji, Tokyo, Japan). Each band was quantitatively determined using the Image J program (http://rsb.info.nih.gov/). The densitometry readings of the bands were normalized to actin expression.

2.8. Cell Motility Assay. 786-O cells were left untreated or treated with 2.5 or $5.0 \mathrm{mg} / \mathrm{mL}$ of $\mathrm{GJH}$ for $24 \mathrm{~h}$ at $37^{\circ} \mathrm{C}$, seeded in a 6-well plate, and grown overnight to confluency in serum-containing medium. The confluent cell layer was scratched with a p200 Eppendorf pipette tip. After $24 \mathrm{~h}$, the closure of the scratch wound was photographed at 400x magnification under a phase contrast microscope (Olympus).

2.9. Cell Invasion Assay. $786-\mathrm{O}$ cells $\left(1 \times 10^{5}\right.$ cells $)$ were resuspended in $300 \mu \mathrm{L}$ medium containing $1 \%$ FBS with various concentrations of $\mathrm{GJH}$ and were then seeded into Transwell inserts $(8 \mu \mathrm{m}$ pore; Millipore) precoated with
TABLE 1: Oligonucleotide sequences used in real-time qRT-PCR.

\begin{tabular}{lc}
\hline Gene & Oligonucleotide sequence \\
\hline ERCC1 & $5^{\prime}$-GGGAATTTGGCGACGTAATTC-3' \\
& $5^{\prime}$-GCGGAGGCTGAGGAACAG-3' \\
TUBB3 & $5^{\prime}$-GCGAGATGTACGAAGACGAC-3' \\
& $5^{\prime}$-TTTAGACACTGCTGGCTTCG-3' \\
Tau & $5^{\prime}$-TGACACGGACGCTGGCCTGAA-3' \\
& $5^{\prime}$-CACTTGGAGGTCACCTTGCTC-3' \\
TS1 & $5^{\prime}$-GGCCTCGGTGTGCCTTT-3' \\
& $5^{\prime}$-GATGTGCGCAATCATGTACGT-3' \\
GAPDH & $5^{\prime}$-TCAACGACCACTTTGTCAAGCT-3' \\
& $5^{\prime}$-GTGAGGGTCTCTCTCTTCCTCTTGT-3' \\
\hline
\end{tabular}

growth factor-reduced Matrigel ( $1 \mu \mathrm{g} / \mathrm{mL}$; BD Biosciences). Complete medium was added to the lower chamber. After incubation for $24 \mathrm{~h}$, invasive cells were fixed, stained, and quantified in 3 random fields (100x magnification) per insert.

2.10. Cell-Cell Adhesion Assay. HUVECs were seeded onto 6well plates and left to grow for $48 \mathrm{~h}$ before experiments. 786O cells were treated with GJH $(1.3-5.0 \mathrm{mg} / \mathrm{mL})$ in serumreduced medium (1\% FBS) for $6 \mathrm{~h}$ and then labeled with the fluorescent dye BCECF/AM (Sigma) at $37^{\circ} \mathrm{C}$ for $30 \mathrm{~min}$. The fluorescence-labeled 786-O cells were pelleted and resuspended $\left(3 \times 10^{4}\right.$ cells $)$ in medium 199 with $10 \mathrm{mM} \mathrm{N}$ 2-hydroxyethylpiperazine- $\mathrm{N}^{\prime}$-2-ethanesulfonic acid buffer (M199H) and added onto the HUVECs layer. After $30 \mathrm{~min}$, cell suspensions were discarded and the adhered labeled 786-O cells were gently washed with $\mathrm{M} 199 \mathrm{H}$. The number of labeled cells was measured using SigmaGel 1.0 (Jandel Scientific). Analyses were repeated 3 times over the same region, and the results presented are the mean values of 3 independent experiments.

2.11. Animal Experiments. All animal experiments were conducted according to the regulations approved by the Institutional Animal Care and Use Committee of the College of Medicine, National Taiwan University. Female nonobese diabetic/severe combined immunodeficient mice (6-8 weeks old) were obtained from the Animal Center of National Taiwan University. 786-O cells $\left(1 \times 10^{6}\right.$ cells $)$ were suspended in $200 \mu \mathrm{L}$ of growth factor-reduced medium and inoculated intravenously into the tail vein of mice weighing 20 to $25 \mathrm{~g}(n=10)$. Two days after injection, the mice were orally administered either water or GJH $(25 \mathrm{~g} / \mathrm{kg})$ daily and weighed every other day ( $n=5$ for each group). After oral administration of GJH for 30 days, the mice were sacrificed and their lungs were excised and weighed to estimate tumor content.

2.12. Electrophoretic Mobility Shift Assay (EMSA). 786-O cells in serum-reduced medium (1\% FBS) were treated with $\mathrm{GJH}(1.3-5.0 \mathrm{mg} / \mathrm{mL})$ for $6 \mathrm{~h}$. Nuclear extracts were prepared using the NE-PER Nuclear Protein Extraction Kit (Thermo 
Scientific). Detection of NF- $\kappa$ B was performed with a biotin-labeled oligo probe containing the proximal NF- $\kappa \mathrm{B}$ recognition site, which spans the region of the human ICAM1 promoter: 5'-GGGAGCCCGGGGAGGATTCCT-3' [15]. For competition experiments, excess cold oligonucleotide probe (2-fold excess and 4-fold excess without biotin label, presented as $2 \times \mathrm{URE}$ and $4 \times \mathrm{URE}$, resp.) was added $15 \mathrm{~min}$ before addition of the labeled probe. Supershift assays were performed with $1 \mu \mathrm{g}$ of the antibody against p65 incubated for $30 \mathrm{~min}$ at $4^{\circ} \mathrm{C}$ after addition of the probe. The reaction products were analyzed via $5 \%$ nondenaturing polyacrylamide gel electrophoresis using $12.5 \mathrm{mM}$ Tris, $12.5 \mathrm{mM}$ boric acid, and $0.25 \mathrm{mM}$ EDTA (pH 8.3), for $4-5 \mathrm{~h}$ at 280 $300 \mathrm{~V} / 10-12 \mathrm{~mA}$. The gels were transferred and blocked as described above. After incubating at room temperature for $1 \mathrm{~h}$ with HRP-conjugated streptavidin (eBioscience), the membranes were washed and visualized as described above.

2.13. Luciferase Reporter Assay. A total of $1 \times 10^{5} 786-\mathrm{O}$ cells were plated in a 6 -well plate for $24 \mathrm{~h}$. Following transfection with $0.1 \mu \mathrm{g}$ of a NF- $\kappa \mathrm{B}$-responsive luciferase reporter for $6 \mathrm{~h}$, the cultures were replated into a 96-well plate at a density of $2 \times 10^{4}$ cells/mL per well. The cells were grown in standard medium for another $18 \mathrm{~h}$ followed by treatment with GJH alone or in combination with TNF- $\alpha$ for $6 \mathrm{~h}$. Luciferase activity was measured using a Luciferase Assay Kit (Stratagene) according to the manufacturer's instructions, using a luminometer (Berthold LB960) and an integration period of $60 \mathrm{~s}$.

2.14. Statistical Analysis. The Image J program (http://rsb .info.nih.gov/) was used for quantization of the expression fold in western blot or EMSA analyses. The fold increase of the indicated proteins was determined by normalizing to actin or Sp1 when they could be detected. SPSS 12.0 for Windows (SPSS Inc.) was used to analyze all data. A twotailed paired-samples Student's $t$-test was used for statistical analysis of comparative data from 2 groups. A $P$ value $<0.05$ was considered statistically significant.

\section{Results}

3.1. Effect of GJH on the Growth of 786-O Renal Carcinoma Cells. To evaluate the effect of GJH on renal cancer cells in vitro, 786-O renal carcinoma cells were exposed to $1-100 \mathrm{mg} / \mathrm{mL}$ of $\mathrm{GJH}$ for $24 \mathrm{~h}$. Cell viability was then determined by MTT assay. After $24 \mathrm{~h}$ of treatment, low doses $(1.0,3.0$, and $10.0 \mathrm{mg} / \mathrm{mL})$ of $\mathrm{GJH}$ increased $786-\mathrm{O}$ cell proliferation, whereas high doses $(>10 \mathrm{mg} / \mathrm{mL})$ caused a decrease in 786-O proliferation (Figure 1). Among the concentrations tested, $3.0 \mathrm{mg} / \mathrm{mL} \mathrm{GJH}$ was the most effective in stimulating 786-O cell proliferation. The growth of 786$\mathrm{O}$ cells decreased in a dose-dependent manner. The value of the $50 \%$ cytotoxic concentration $\left(\mathrm{CC}_{50}\right)$ for $24 \mathrm{~h}$ of treatment was determined to be $35 \pm 0.5 \mathrm{mg} / \mathrm{mL}$. These findings indicate that low concentrations of GJH induce the proliferation of 786-O cells, while high doses of GJH are cytotoxic for 786-O cells.

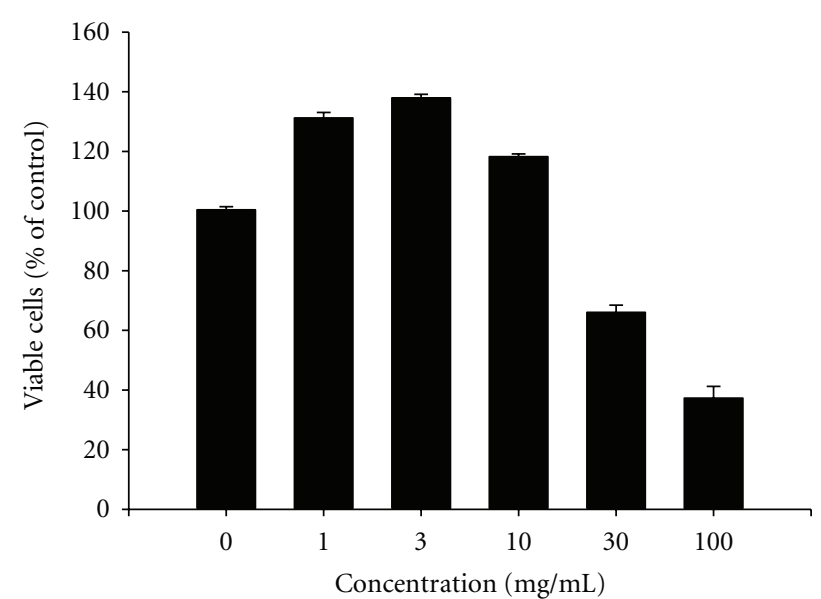

FIGURE 1: Biphasic effects of GJH on cell viability in 786-O cells. Cells were incubated with GJH $(1-100 \mathrm{mg} / \mathrm{mL})$ for $24 \mathrm{~h}$. The viability of cells was determined by MTT assay. Low concentrations $(1-10 \mathrm{mg} / \mathrm{mL})$ of $\mathrm{GJH}$ increase whereas high concentrations $(>10 \mathrm{mg} / \mathrm{mL})$ repress cell proliferation. The mean (SD) is shown from at least 3 separate experiments. ${ }^{* * *} P<0.001$.

\subsection{Effects of GJH Supplementation on the Anticancer Action of} 5-FU In Vitro. To explore the potentially useful combination of GJH with chemotherapeutic agents commonly used in renal cancer therapy, we assessed the interaction between GJH and several chemotherapeutic agents in 786-O cells. The synergistic analysis indicated that GJH had a synergistic effect on the cytotoxicity of 5 -FU in a relatively broad dose inhibition range (30-75\% fraction affected in $786-\mathrm{O}$ cells; Figures 2(a) and 2(b)), while no synergistic interaction between GJH and cisplatin or paclitaxel was observed (data not shown). Biotin-Annexin $\mathrm{V}$ binding was detected in target cells as an index for the translocation of PSer from the inner to the outer monolayer of the cell surface membrane (flipflop) that happens during the early stages of apoptosis. The $3 \% \mathrm{H}_{2} \mathrm{O}_{2}$ treated group showed a relatively high intensity of binding (absorbance, $\sim 1.3$ at $450 \mathrm{~nm}$ ) that served as a positive control. As shown in Figure 2(c), the negative control (PBS treatment) showed $\sim 3.3 \%$ of the apoptotic response seen in the $3 \% \mathrm{H}_{2} \mathrm{O}_{2}$ group. Although $\mathrm{GJH}$ (at $12.5 \%$ and $25 \%$ cytotoxic concentration, $\mathrm{CC}_{12.5}$ and $\mathrm{CC}_{25}$, resp.) slightly enhanced apoptotic responses (5.2\% and 6.5\% of the $\mathrm{H}_{2} \mathrm{O}_{2}$ group, resp.), the combination of $\mathrm{GJH}$ and 5-FU $\left(\mathrm{CC}_{12.5}\right.$ or $\mathrm{CC}_{25}$ for both treatments) induced significantly stronger apoptotic responses $\left(18.7 \%\right.$ and $32.1 \%$ of the $\mathrm{H}_{2} \mathrm{O}_{2}$ group, resp.) when compared to 5-FU alone $\left(\mathrm{CC}_{12.5}\right.$ and $\mathrm{CC}_{25}$ were $8.55 \%$ and $19.4 \%$, resp. of the $\mathrm{H}_{2} \mathrm{O}_{2}$ group).

We also investigated the influence of GJH on chemotherapeutic agent-associated gene expression. GJH in combination with 5-FU could significantly suppress the expression levels of chemotherapeutic agent resistance-related genes in 786-O cells. Real-time quantitative RT-PCR showed that GJH significantly enhances the alternation of chemotherapeutic agent resistance-related genes: upregulation of excision repair cross-complementing gene 1 (ERCC1) and 


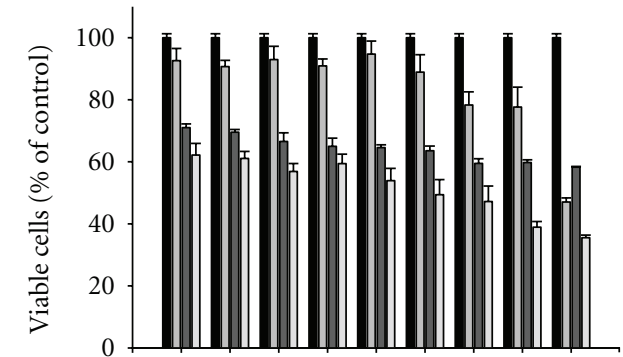

GJH $(\mathrm{mg} / \mathrm{mL}) \quad 3.9 \quad 4.4 \quad 5 \quad 5.8 \quad 7 \quad 8.8 \quad 11.717 .5 \quad 35$

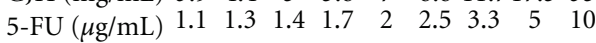

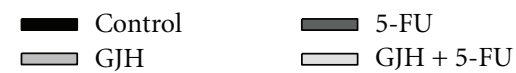

(a)

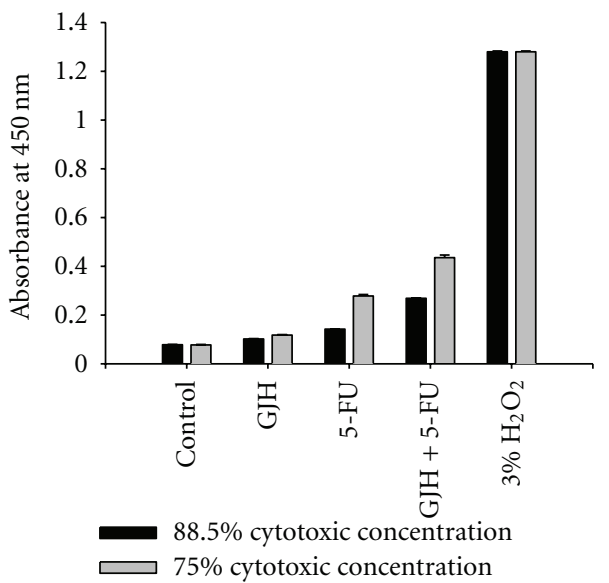

(c)

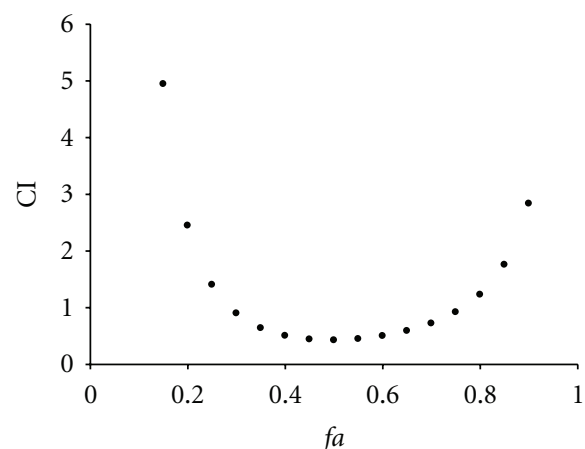

(b)

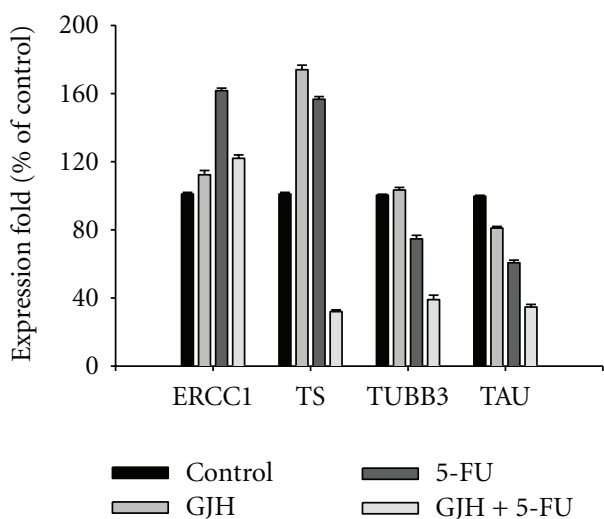

(d)

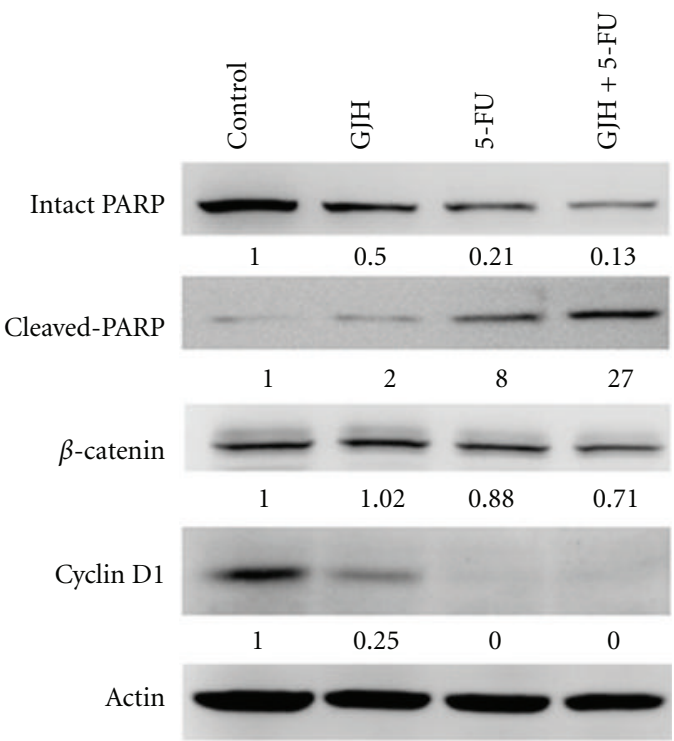

(e)

FIGURE 2: Synergistic effect between GJH and 5-FU on 786-O cancer cell apoptosis. (a) A dose-response survival curve for GJH and the chemotherapeutic agent 5-FU in 786-O cells. (b) $\mathrm{CI}$ values at different levels of growth inhibition effect $(f a)$. (c) $\mathrm{GJH}\left(\mathrm{CC}_{12.5}\right.$ and $\mathrm{CC}_{25}$ ) enhances the apoptotic response to 5-FU $\left(\mathrm{CC}_{12.5}\right.$ and $\mathrm{CC}_{25}$, resp.) as demonstrated by Annexin V-binding assay. (d) Combination treatment with GJH and 5-FU upregulates the expression of ERCC1 but downregulates the expression of TUBB3, Tau, and TS1 as shown by real-time quantitative RT-PCR. (e) Western blot analysis indicates that $\mathrm{GJH}\left(\mathrm{CC}_{25}\right)$ enhances the 5-FU $\left(\mathrm{CC}_{25}\right)$-induced cleavage of PARP, as well as 5 -FU-induced reduction in expression of $\beta$-catenin and cyclin D1. The mean (SD) is shown from at least 3 separate experiments. 
downregulation of thymidylate synthase 1 (TS), class III $\beta$ tubulin (TUBB3), and microtubule-associated protein tau (Tau), respectively, ( $\mathrm{CC}_{25}$ of $\mathrm{GJH}+\mathrm{CC}_{25}$ of 5 -FU was more effective than either $\mathrm{CC}_{25}$ of $\mathrm{GJH}$ or $\mathrm{CC}_{25}$ of 5 -FU alone; Figure $2(\mathrm{~d})$ ). In addition, western blot analysis indicated that GJH enhanced 5-FU-induced cleavage of PARP, as well as 5FU-induced reduction in expression of $\beta$-catenin and cyclin D1 $\left(\mathrm{CC}_{25}\right.$ of $\mathrm{GJH}+\mathrm{CC}_{25}$ of 5 -FU was more effective than either $\mathrm{CC}_{25}$ of $\mathrm{GJH}$ or $\mathrm{CC}_{25}$ of 5 -FU alone; Figure $\left.2(\mathrm{e})\right)$. These results indicate that a useful synergistic interaction exists between GJH and 5-FU in 786-O renal cancer cells. Possible mechanisms for this synergy may include the alternation of chemotherapeutic agent resistance-related genes and synergistic effects on apoptosis.

3.3. Antimetastatic Effect of GJH in 786-O Cells In Vitro and In Vivo . Cell adhesion and migration are important factors to consider when investigating the metastatic potential of cancer cells. Adhesion to extracellular matrices is considered to be a pivotal step in the invasive process of metastatic cells. To investigate the potential effect of GJH on metastasis, we first examined the adhesion of 786-O cells to confluent monolayers of HUVECs in 6-well plates after exposure of the cells to $\mathrm{GJH}$ for $6 \mathrm{~h}$. A significant reduction in adhesion was observed in GJH (1.3-5.0 mg/mL)-treated cells when compared with the control cells $(69.7 \%$ reduction after $5.0 \mathrm{mg} / \mathrm{mL}$ GJH treatment; Figure 3(a); $P<0.001)$. The inhibition of 786-O cell migration was examined using a wound healing assay, and the results are shown in Figure 3(b). Phase-contrast images were taken at 6 and $12 \mathrm{~h}$. Longer $(12 \mathrm{~h})$ incubation with GJH $(2.5$ and $5.0 \mathrm{mg} / \mathrm{mL})$ led to greater inhibition of cell migration in 786-O cells. A Matrigel invasion assay was performed to determine the antiinvasive effect of GJH in 786-O cells. After $24 \mathrm{~h}$ of incubation, GJH (1.3-5.0 mg/mL)-treated cells showed a decreased level of invasion compared to control cells $(83.7 \%$ reduction after $5.0 \mathrm{mg} / \mathrm{mL}$ GJH treatment; Figure 3(c); $P<0.01$ ).

The effects of GJH on cell metastasis were then examined. Animal experiments showed that oral administration of GJH ( $25 \mathrm{~g} / \mathrm{kg}$ per day) significantly reduced metastatic tumor nodules in the lungs during a 30-day follow-up period $(542.0 \pm 124.5 \mathrm{mg}$ versus $243.0 \pm 52.6 \mathrm{mg}$ in control group and GJH treated group, resp.; Figure 3(d); $P<0.01)$. In addition, the dosage used in vivo did not have any significant toxic effects and did not significantly alter body weight during the 30-day experimentation period $(79.6 \pm 8.1 \%$ versus $94.9 \pm 11.3 \%$ in control group and GJH treated group, resp.; Figure 3(e); $P>0.05)$. Taken together, these results support the idea that GJH inhibits renal cancer metastasis in vitro and in vivo.

3.4. Downregulation of ICAM-1 Expression and Reduction in $N F-\kappa B$ Transcriptional Activity Are Involved in GJH-Mediated Anticancer Effects. It is known that cancer cell-endothelial cell interactions are regulated in part by the expression of specific adhesion molecules on the cell surface, such as ICAM-1. Therefore, the expression of ICAM-1 was examined in GJH-treated and untreated cells. Western blot analysis indicated that GJH significantly reduces the expression of ICAM-1 in both dose- and time-dependent manners (Figure $4(\mathrm{a})$ ). Since aberrant regulation of the transcription factor NF- $\kappa$ B and its signaling pathways are involved in cancer development and progression $[16,17]$, and the induction of ICAM-1 involves activation of NF- $\kappa$ B, the effects of GJH on NF- $\kappa \mathrm{B}$ were examined. Whole cell lysates or nuclear extracts of 786-O cells with or without GJH treatment were prepared, and the expression and the nuclear translocation of NF- $\kappa$ B protein were analyzed. Western blot analysis showed that the amounts of $\mathrm{p} 65$ and $\mathrm{p} 50 \mathrm{NF}-\kappa \mathrm{B}$ subunits in the nuclear fraction were significantly reduced in both whole cell lysate and nuclear fraction of 786-O cells after GJH treatment (Figure 4(b)). Meanwhile, by investigating the NF$\kappa \mathrm{B}$ binding activity to the ICAM-1 promoter, EMSA analysis showed that the DNA-binding activity of NF- $\kappa \mathrm{B}$ to the ICAM-1 promoter was decreased by GJH treatment $(50.1 \%$ reduction after $5.0 \mathrm{mg} / \mathrm{mL}$ GJH treatment; Figure $4(\mathrm{c})$ ). To quantify binding activity, a luciferase reporter containing the $\mathrm{NF}-\kappa \mathrm{B}$ binding region was introduced into $786-\mathrm{O}$ cells. NF$\kappa \mathrm{B}$-induced luciferase activity was reduced by $61.8 \%, 79.8 \%$, and $94.1 \%$ after treatment with $1.3,2.5$, and $5.0 \mathrm{mg} / \mathrm{mL} \mathrm{GJH}$, respectively, (Figure $4(\mathrm{~d})$, black bar). TNF- $\alpha(10 \mathrm{ng} / \mathrm{mL})$ increased the activity of NF- $\kappa \mathrm{B}$ by 2.77 -fold; this was reduced by $58.1 \%, 76.8 \%$, and $82.5 \%$ by $1.3,2.5$, and $5.0 \mathrm{mg} / \mathrm{mL}$ GJH, respectively, (Figure 4(d), white bar). It is known that TNF- $\alpha$ plays a role in the induction of ICAM-1 expression via activation of NF- $\kappa$ B. Therefore, these results imply that GJH downregulates TNF- $\alpha$-dependent and TNF- $\alpha$-independent ICAM-1 expression, in part by reducing the expression and inactivating the transcriptional activity of NF- $\kappa \mathrm{B}$.

\section{Discussion}

Although many anticancer drugs are used clinically, they generally induce strong cellular cytotoxicity and related side effects. A cancer drug with little or no toxicity to normal cells is required. Many studies have shown that GJH has a variety of therapeutic effects [7-12]. However, the effects of water-based extracts of GJH in human cancers have not been determined. In the present study, we explored the anticancer effects of a water-based extract of GJH. The molecular mechanisms of GJH action involve the downregulation of chemotherapeutic agent resistancerelated genes and ICAM-1 expression, in parallel with the reduction of NF- $\kappa \mathrm{B}$ expression and activation in 786-O renal carcinoma cells. This results in a synergistic effect on 5FU-induced apoptosis, inhibition of cancer cell migration and invasion, and adherence of cancer cells to HUVECs. To the best of our knowledge, the present study is the first to demonstrate the therapeutic potential of GJH in human renal carcinoma. According to the compatibility of Chinese herbal medicine, GJH belongs to a monarch formula, which may need an assistant or a guide formulas to form a prescription. The potential clinical applications of GJH may include enhancement of drug targeting as well as decreased side effects in renal cancer patients.

The adhesion molecule ICAM-1 plays an important role in the regulation of cellular inflammatory responses [8] and transduces several intracellular signal transduction 


$$
\text { GJH }
$$
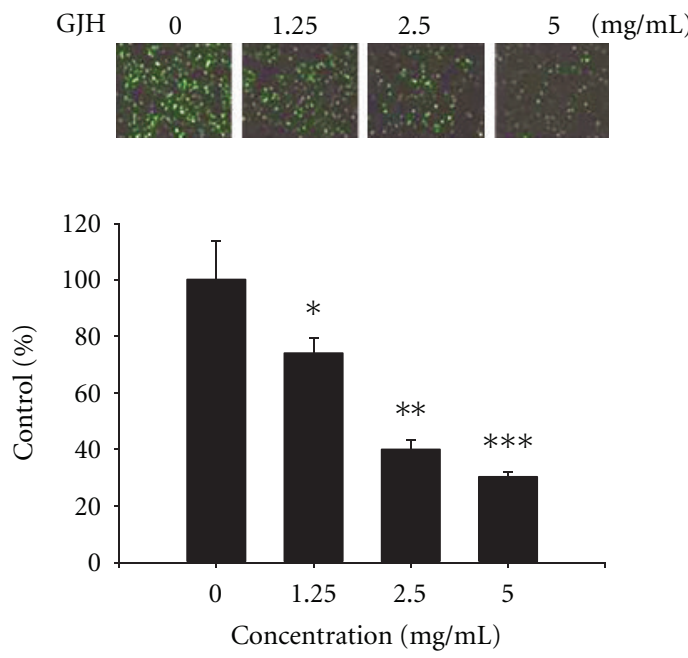

(a)
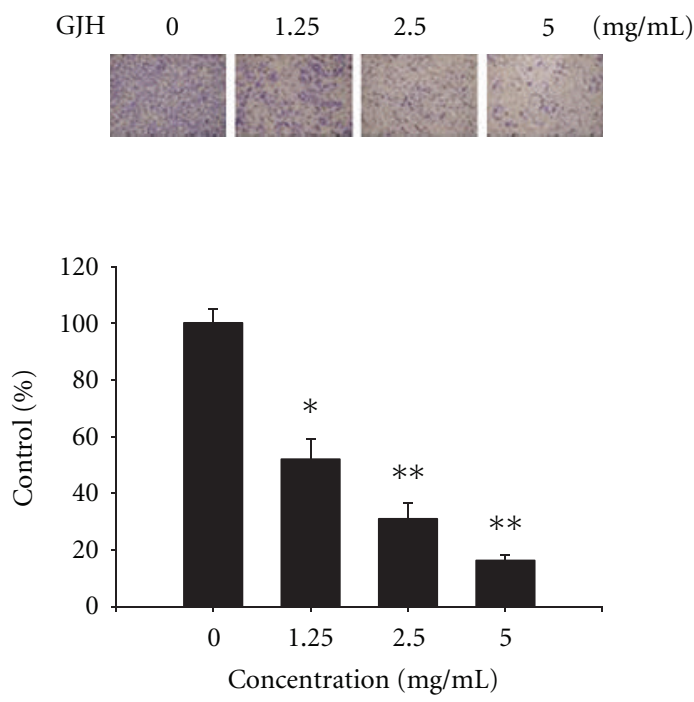

(c)

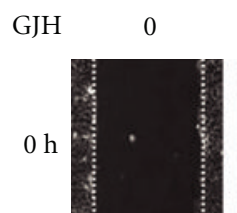

2.5
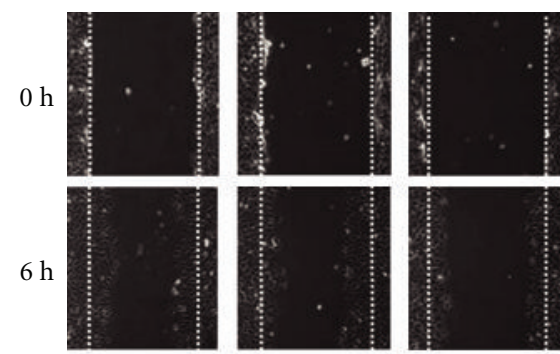

$12 \mathrm{~h}$
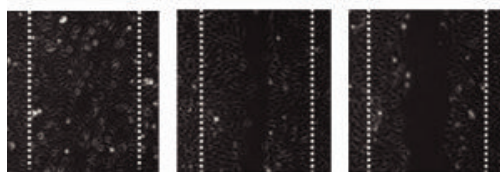

(b)

$$
\text { Control }
$$

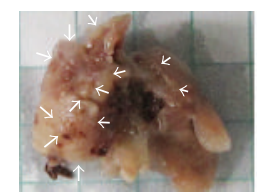

GJH $(25 \mathrm{~g} / \mathrm{kg})$
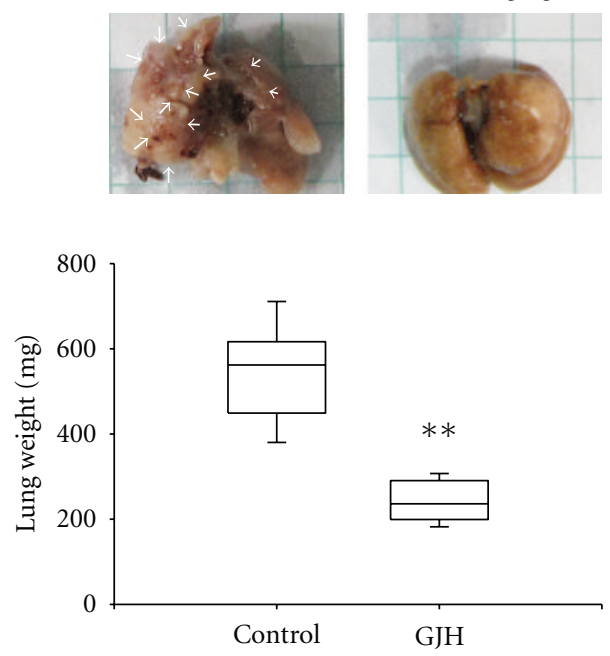

(d)

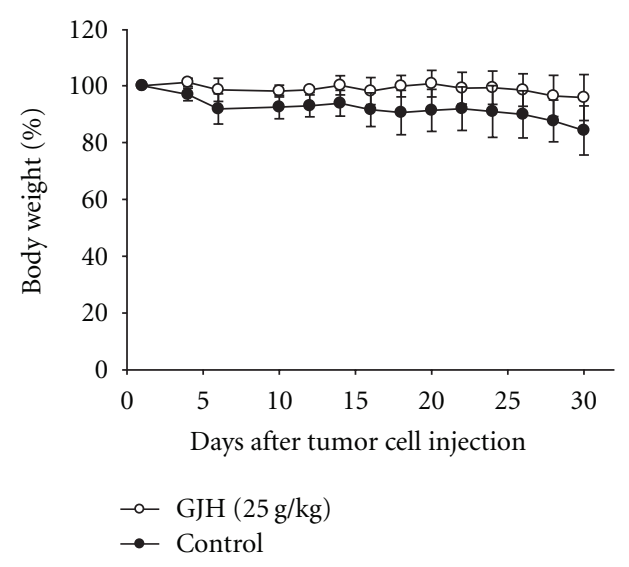

(e)

FIGURE 3: Antimetastatic effect of GJH on $786-\mathrm{O}$ cells. GJH $(1.3-5.0 \mathrm{mg} / \mathrm{mL})$ significantly reduced the (a) adhesion of $786-\mathrm{O}$ cells to HUVECs, the (b) migration and (c) invasion of 786-O cells. (d) Animal experiments showed that oral administration of GJH (25 g/kg per day for a total of 30 days) significantly reduces metastatic tumor nodules in the lungs as demonstrated by lung weight. (e) There was no significant difference in body weight between mice treated with (open circle) and without (closed circle) GJH. The mean (SD) is shown from at least 3 experiments. ${ }^{*} P<0.05,{ }^{* *} P<0.01,{ }^{* * *} P<0.001$. 


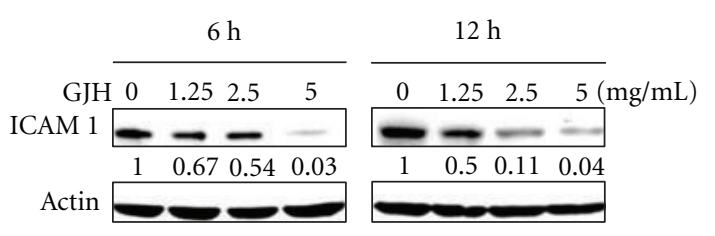

(a)

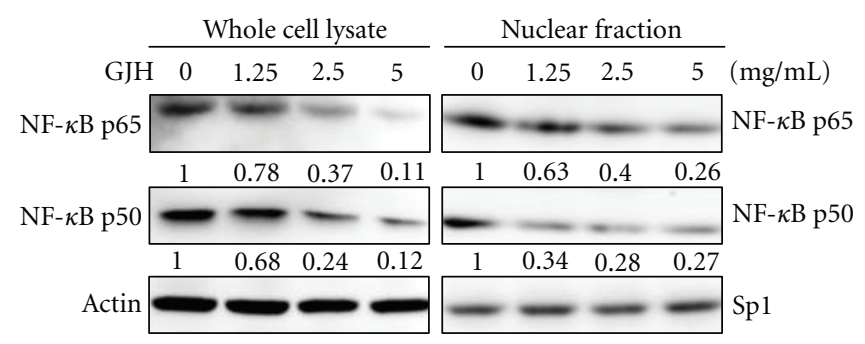

(b)

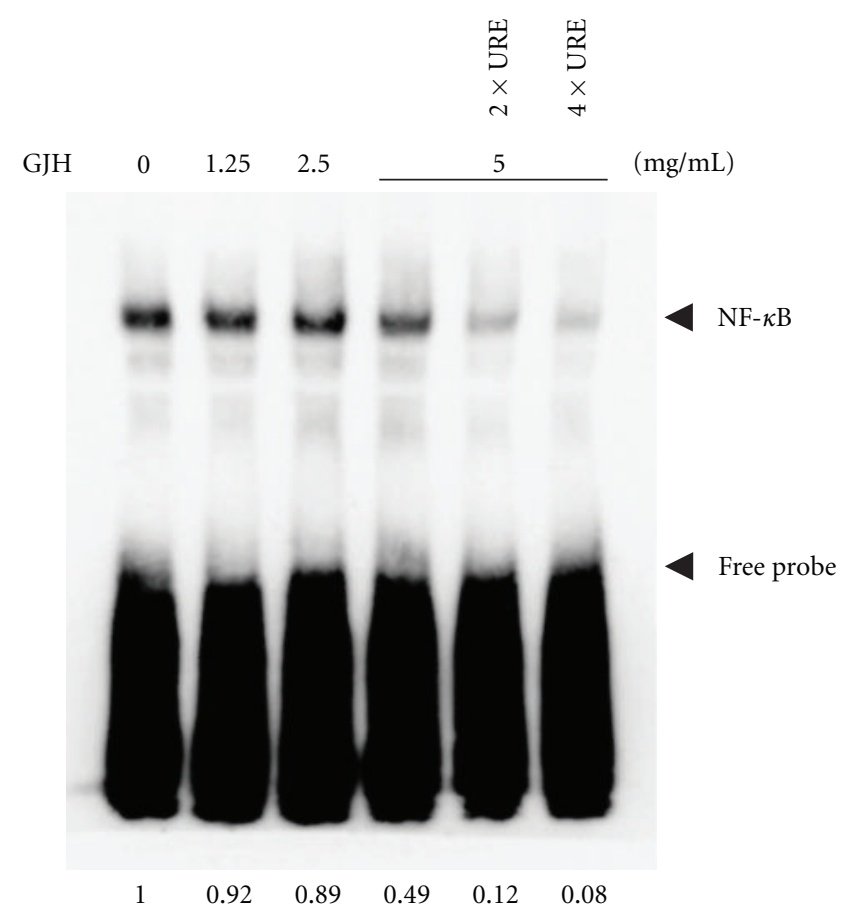

(c)

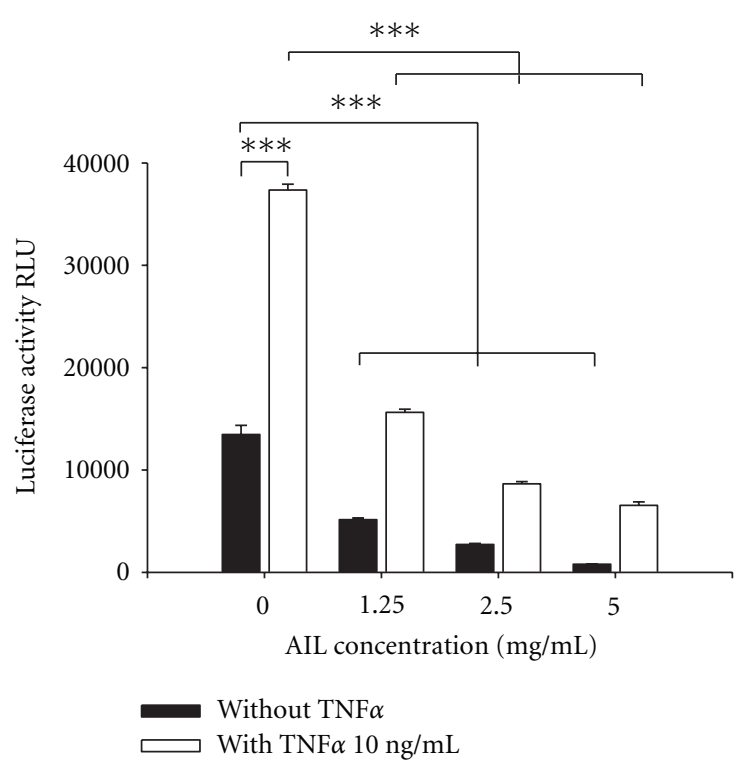

(d)

FIGURE 4: GJH downregulates the expression of ICAM-1 through reduction of the expression and transcriptional activity of NF- $\kappa$ B. (a) GJH significantly reduces the expression of ICAM-1 in both dose- and time-dependent manners, as shown by western blot analysis. (b) Western blotting reveals that GJH reduces the amounts and the nuclear translocation of NF- $\kappa \mathrm{B}$ p 65 and p50 subunits in the cells. (c) GJH reduces the DNA-binding activity of NF- $\kappa$ B to ICAM- 1 as shown by EMSA analysis. (d) GJH downregulates TNF- $\alpha$-dependent and TNF- $\alpha$-independent ICAM-1 expression in part through NF- $\kappa$ B as demonstrated by the luciferase reporter assay. The mean (SD) is shown from at least 3 separate experiments. ${ }^{* * *} P<0.001$.

pathways. Its expression is activated by immunotherapeutic agents such as TNF- $\alpha$, alone or in combination with other interleukins, in patients with renal cancer [18-25]. The present study shows that GJH can reduce cancer cell motility in vitro and in vivo. In addition, the inhibition of oncogenic functions including the adhesion of cancer cells to endothelial cells, cell migration, and cell invasion by $\mathrm{GJH}$ occurred concurrently with the reduction of ICAM1 expression. This indicates that ICAM-1 expression may be of functional importance in cancer cell adhesion and motility. Our preliminary data indicated that a high content of apigenin was detected in the water-based extract of GJH (Figure 1 of Supplementary Material available at doi: $10.1155 / 2012 / 935860$ ), and in GJH-induced cytoskeleton rearrangement through downregulation of Rac 1 expression (Figure 2 of Supplementary Material). These results suggest that apigenin may be one of the major active anticancer components of GJH. Although the detailed contents of GJH and their molecular mechanisms need to be investigated further, these results provide information related to the ability of GJH extracts to arrest cell motility in renal cancer cells, supporting its potential to inhibit metastatic renal tumors.

On the other hand, the death and growth of cells are balanced by the opposing processes of cellular apoptosis and proliferation, respectively, under normal conditions. Inhibition of uncontrolled cell proliferation and/or enhancement of cellular apoptosis may help to maintain normal cellular homeostasis and decrease the chances of neoplastic progression. Our results demonstrate a biphasic effect of $\mathrm{GJH}$ on the growth of cultured human renal cancer cells and only showed significant inhibition of growth at higher concentrations. Some phytochemicals, such as curcumin and apigenin, also show biphasic effects in cultured cells; 
low concentrations stimulate cell proliferation, whereas high concentrations are cytotoxic $[26,27]$. One reason for this may be the involvement of distinct kinases or growth factors at different concentrations of GJH. Although the reason for this differential effect of GJH on renal cancer cells remains to be determined, the current study evaluated the synergistic effect of GJH in combination with 5-FU, but not cisplatin and paclitaxel, in apoptosis. Similarly to the way that the importance of food synergy (the perspective of evaluating whole foods rather than single food components) has been clarified $[28,29]$, the synergistic effect supports the use of $\mathrm{GJH}$ in combination with 5-FU during cancer therapy.

In conclusion, the present study shows that GJH has a synergistic effect on 5-FU-mediated apoptosis and inhibits cell adhesion and motility. The results of this study support the potential of GJH as a useful chemotherapeutic agent for the treatment of renal cancer. Its clinical application warrants further investigations into the molecular mechanisms and beneficial effects of GJH.

\section{Acknowledgments}

The authors thank Dr. Zee-Fen Chang (National Yang-Ming University) for providing the GST-PAK1-PBD construct and Dr. Si-Xue Sun (Bureau of Standards, Metrology and Inspection, Ministry of Economic Affairs) for technical support with LC-MS analysis. This study was supported by Grants from the Committee on Chinese Medicine and Pharmacy (CCMP-96-RD-203-1) and the Department of Health (DOH97-TD-I-111-TM018, DOH98-TD-I-111TM020), Executive Yuan, Taiwan. Y.-H. Liu, M.-L. Li, and M.-Y. Hsu contributed equally to this work.

\section{References}

[1] B. Ljungberg, N. C. Cowan, D. C. Hanbury et al., "EAU guidelines on renal cell carcinoma: the 2010 update," European Urology, vol. 58, no. 3, pp. 398-406, 2010.

[2] K. Homicsko and D. R. Berthold, "Neoadjuvant and adjuvant strategies in renal cell carcinoma: more questions than answers," Anti-Cancer Drugs, vol. 22, supplement 1, pp. S4S8, 2011.

[3] M. E. Gore and J. M. Larkin, "Challenges and opportunities for converting renal cell carcinoma into a chronic disease with targeted therapies," British Journal of Cancer, vol. 104, no. 3, pp. 399-406, 2011.

[4] M. Iiizumi, W. Liu, S. K. Pai, E. Furuta, and K. Watabe, "Drug development against metastasis-related genes and their pathways: a rationale for cancer therapy," Biochimica et Biophysica Acta, vol. 1786, no. 2, pp. 87-104, 2008.

[5] R. L. Scherer, J. O. McIntyre, and L. M. Matrisian, "Imaging matrix metalloproteinases in cancer," Cancer and Metastasis Reviews, vol. 27, no. 4, pp. 679-690, 2008.

[6] L. A. Liotta, "Tumor invasion and metastases-role of the extracellular matrix: rhoads memorial award lecture," Cancer Research, vol. 46, no. 1, pp. 1-7, 1986.

[7] J. G. Chai, T. Bando, S. Kobashi et al., "An extract of seeds from Aeginetia indica L., a parasitic plant, induces potent antigenspecific antitumor immunity in Meth A-bearing BALB/c mice," Cancer Immunology Immunotherapy, vol. 35, no. 3, pp. 181-185, 1992.
[8] J. G. Chai, M. Okamoto, T. Bando et al., "Dissociation between the mitogenic effect and antitumor activity of seed extract from Aeginetia indica L," Immunopharmacology, vol. 30, no. 3, pp. 209-215, 1995.

[9] J. G. Chai, T. Bando, H. Nagasawa, K. Himeno, M. Sato, and S. Ohkubo, "Seed extract of Aeginetia indica L induces cytokine production and lymphocyte proliferation in vitro," Immunopharmacology, vol. 27, no. 1, pp. 13-21, 1994.

[10] M. Okamoto, G. Ohe, T. Oshikawa et al., "Purification and characterization of cytokine-inducing protein of seed extract from Aeginetia indica L., a parasitic plant," Immunopharmacology, vol. 49, no. 3, pp. 377-389, 2000.

[11] G. Ohe, M. Okamoto, T. Oshikawa et al., "Th1-cytokine induction and anti-tumor effect of $55 \mathrm{kDa}$ protein isolated from Aeginetia indica L., a parasitic plant," Cancer Immunology, Immunotherapy, vol. 50, no. 5, pp. 251-259, 2001.

[12] M. Okamoto, E. G. Oh, T. Oshikawa et al., "Toll-like receptor 4 mediates the antitumor host response induced by a 55 kilodalton protein isolated from Aeginetia indica L., a parasitic plant," Clinical and Diagnostic Laboratory Immunology, vol. 11, no. 3, pp. 483-495, 2004.

[13] T. C. Chou and P. Talalay, "Quantitative analysis of doseeffect relationships: the combined effects of multiple drugs or enzyme inhibitors," Advances in Enzyme Regulation, vol. 22, pp. 27-55, 1984.

[14] K. J. Livak and T. D. Schmittgen, "Analysis of relative gene expression data using real-time quantitative PCR and the 2$(\Delta \Delta \mathrm{C}(\mathrm{T}))$ method," Methods, vol. 25, no. 4, pp. 402-408, 2001.

[15] F. Aoudjit, N. Brochu, B. Belanger, C. Stratowa, J. Hiscott, and M. Audette, "Regulation of intercellular adhesion molecule1 gene by tumor necrosis factor- $\alpha$ is mediated by the nuclear factor- $\kappa$ B heterodimers p65/p65 and p65/c-Rel in the absence of p50," Cell Growth and Differentiation, vol. 8, no. 3, pp. 335342, 1997.

[16] J. Inoue, J. Gohda, T. Akiyama, and K. Semba, "NF- $\kappa$ B activation in development and progression of cancer," Cancer Science, vol. 98, no. 3, pp. 268-274, 2007.

[17] M. Karin and F. R. Greten, "NF- $\kappa$ B: linking inflammation and immunity to cancer development and progression," Nature Reviews Immunology, vol. 5, no. 10, pp. 749-759, 2005.

[18] P. Ziprin, P. F. Ridgway, K. L. Pfistermuller, D. H. Peck, and A. W. Darzi, "ICAM-1 mediated tumor-mesothelial cell adhesion is modulated by IL- 6 and TNF- $\alpha$ : a potential mechanism by which surgical trauma increases peritoneal metastases," Cell Communication and Adhesion, vol. 10, no. 3, pp. 141-154, 2003.

[19] C. C. Zielinski, A. C. Budinsky, T. M. Wagner et al., "Defect of tumour necrosis factor- $\alpha$ (TNF- $\alpha$ ) production and TNF- $\alpha$ induced ICAM-1- expression in BRCA1 mutations carriers," Breast Cancer Research and Treatment, vol. 81, no. 2, pp. 99105, 2003.

[20] V. Forest, F. Pierre, E. Bassonga, K. Meflah, C. Olivier, and J. Menanteau, "Apc+/Min colonic epithelial cells express TNF receptors and ICAM-1 when they are co-cultured with large intestine intra-epithelial lymphocytes," Cellular Immunology, vol. 223, no. 1, pp. 70-76, 2003.

[21] J. Viac, C. Vincent, S. Palacio, D. Schmitt, and A. Claudy, "Tumour Necrosis Factor (TNF) soluble receptors in malignant melanoma: correlation with soluble ICAM-1 levels," European Journal of Cancer, vol. 32, no. 3, pp. 447-449, 1996.

[22] C. Fortis, L. Galli, G. Consogno et al., "Serum levels of soluble cell adhesion molecules (ICAM-1, VCAM-1, E-selectin) and 
of cytokine TNF- $\alpha$ increase during interleukin-2 therapy," Clinical Immunology and Immunopathology, vol. 76, no. 2, pp. 142-147, 1995.

[23] S. Bauer, J. C. Oosterwijk-Wakka, N. Adrian et al., "Targeted therapy of renal cell carcinoma: synergistic activity of cG250TNF and IFNg," International Journal of Cancer, vol. 125, no. 1, pp. 115-123, 2009.

[24] Y. Mizutani, B. Bonavida, Y. Nio, and O. Yoshida, "Overcoming TNF- $\alpha$ and drug resistance of human renal cell carcinoma cells by treatment with pentoxifylline in combination with TNF- $\alpha$ or drugs: the role of TNF- $\alpha$ mRNA downregulation in tumor cell sensitization," Journal of Urology, vol. 151, no. 6, pp. 1697-1702, 1994.

[25] G. G. Hillman, R. K. Puri, M. A. Kukuruga, J. E. Pontes, and G. P. Haas, "Growth and major histocompatibility antigen expression regulation by IL-4, interferon- $\gamma($ IFN- $\gamma$ ) and tumour necrosis factor- $\alpha$ (TNF- $\alpha$ ) on human renal cell carcinoma," Clinical and Experimental Immunology, vol. 96, no. 3, pp. 476-483, 1994.

[26] S. J. Kim, T. G. Son, H. R. Park et al., "Curcumin stimulates proliferation of embryonic neural progenitor cells and neurogenesis in the adult hippocampus," Journal of Biological Chemistry, vol. 283, no. 21, pp. 14497-14505, 2008.

[27] X. Long, M. Fan, R. M. Bigsby, and K. P. Nephew, "Apigenin inhibits antiestrogen-resistant breast cancer cell growth through estrogen receptor- $\alpha$-dependent and estrogen receptor- $\alpha$-independent mechanisms," Molecular Cancer Therapeutics, vol. 7, no. 7, pp. 2096-2108, 2008.

[28] D. R. Jacobs Jr., M. D. Gross, and L. C. Tapsell, "Food synergy: an operational concept for understanding nutrition," American Journal of Clinical Nutrition, vol. 89, no. 5, pp. 1543S1548S, 2009.

[29] D. R. Jacobs Jr. and L. C. Tapsell, "Food, not nutrients, is the fundamental unit in nutrition," Nutrition Reviews, vol. 65, no. 10, pp. 439-450, 2007. 


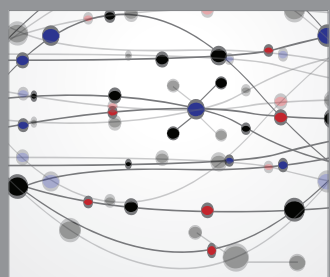

The Scientific World Journal
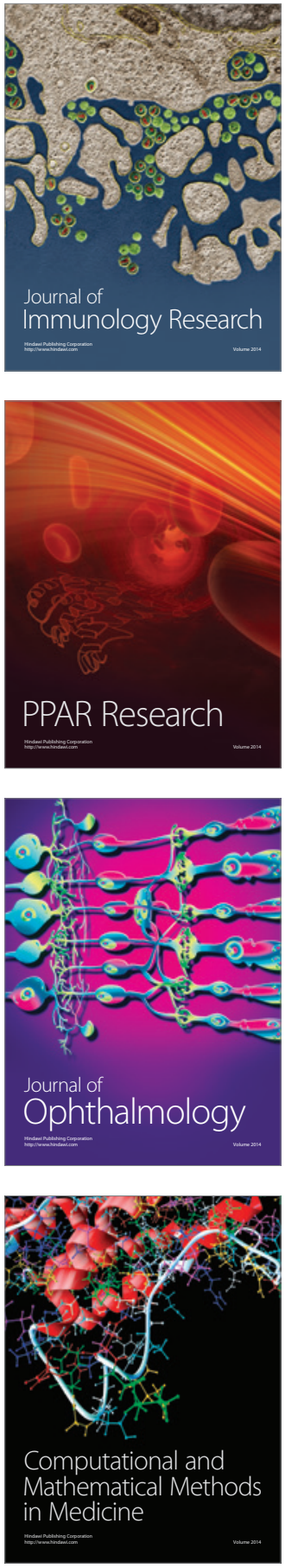

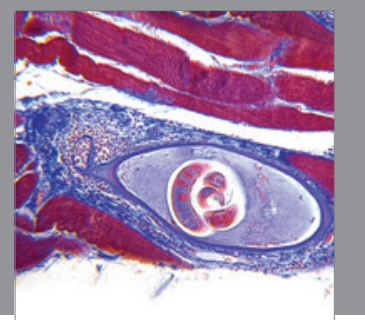

Gastroenterology

Research and Practice
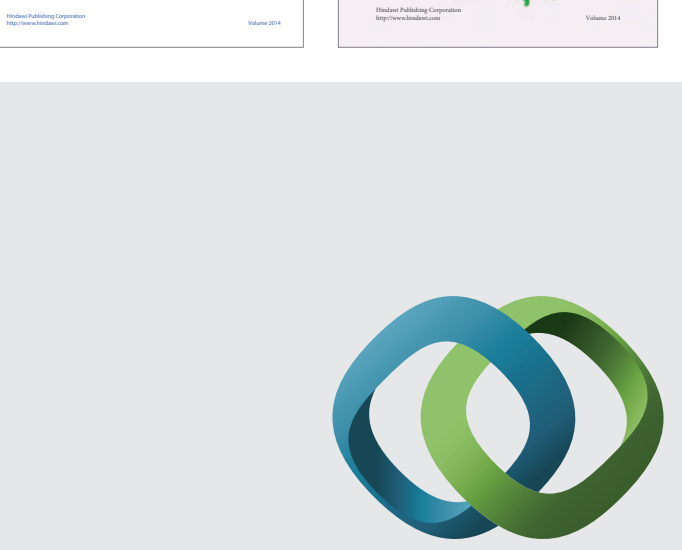

\section{Hindawi}

Submit your manuscripts at

http://www.hindawi.com
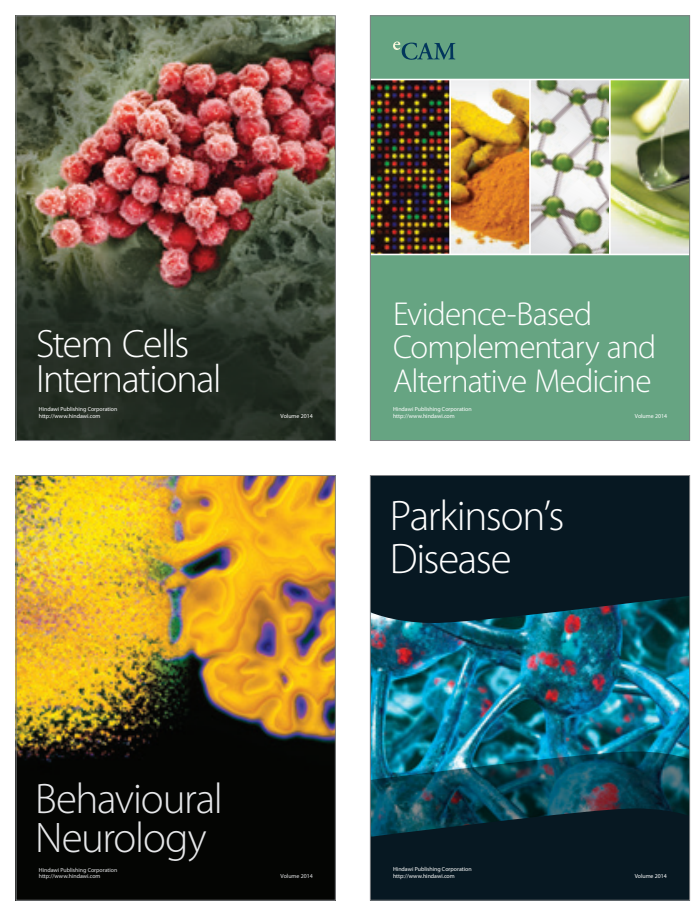

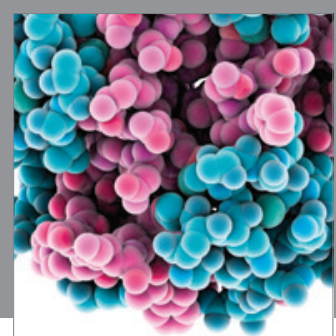

Journal of
Diabetes Research

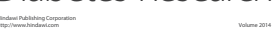

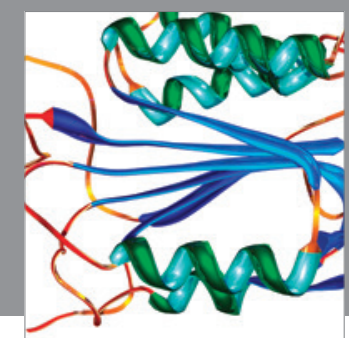

Disease Markers
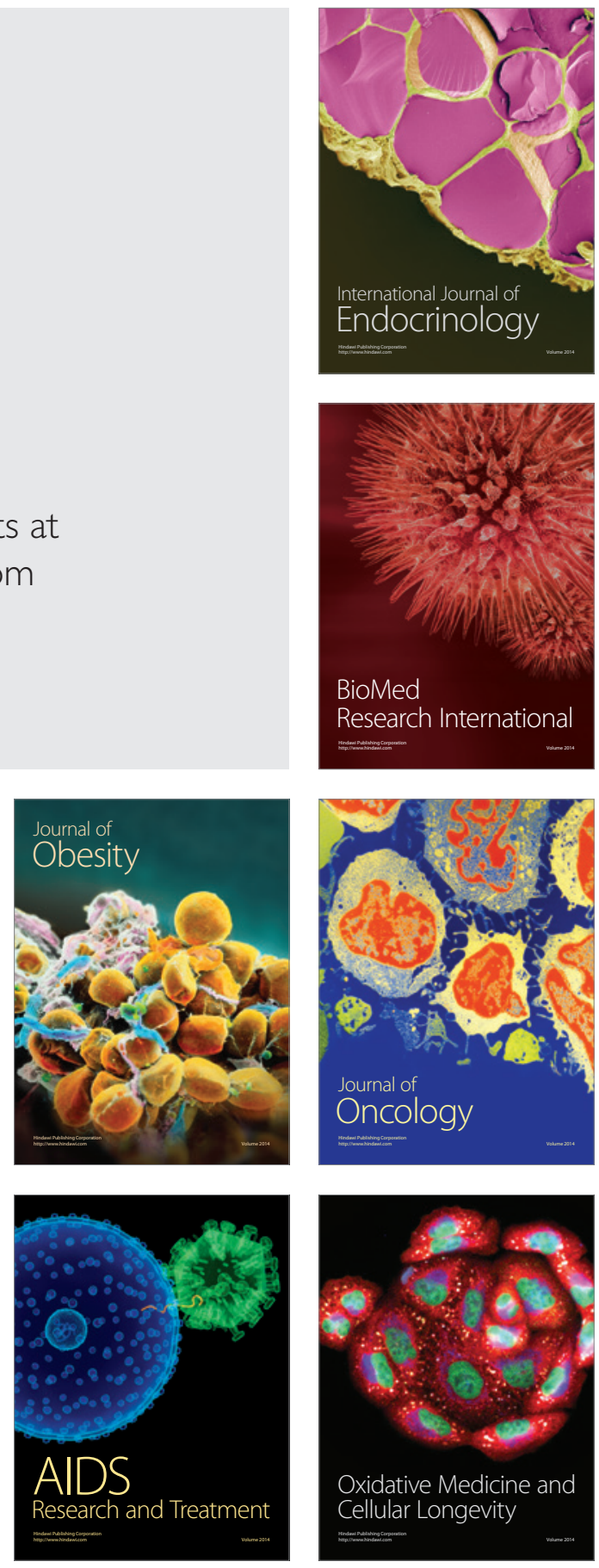